\title{
Por dentro do ringue: gênero e sexualidade no embate da inclusão por direitos ${ }^{1}$
}

\author{
Por: María Elvira Díaz-Benítez e Nathalia Ferreira Gonçales ${ }^{2}$
}

\section{Resumo:}

Este ensaio busca refletir sobre os diversos golpes que têm acontecido nas últimas duas décadas em relação às políticas de gênero e sexualidade no Brasil, enfatizando sobre Aborto; o Programa Brasil sem Homofobia; os projetos de "Cura Gay"; a Lei João W. Nery para transexuais; a Lei Gabriela Leite e o embate ao redor da legislação da prostituição; a ideologia de gênero e sua inclusão nos planos curriculares e o Estatuto da família.

Palavras-chaves: Gênero; Sexualidade; Direitos; Inclusão Social.

\section{Inside the ring: gender and sexuality fighting for rights' inclusion}

\begin{abstract}
:
This essay aims to reflect about many coups that have occoured in the last two decades in relation to the policies of gender and sexuality in Brazil, emphatisizing abortion; Brazil without homofobia program; The "gay cure" law projects; João W. Nery's law for transgenders; Gabriela Leite's law and the fight around the legislation of prostitution; gender's ideology and its inclusion in the curricular plans and the Family Statute law project.
\end{abstract}

Keywords: Gender; sexuality; Rights; Social Inclusion.

Para além das fronteiras nacionais, uma das principais imagens que surgem ao pensar no Brasil seria uma suposta sexualidade desenfreada. Segundo o imaginário do estrangeiro, aqui o sexo e as sexualidades teriam características próprias, excepcionais, compondo um território de proezas e exotismo. Esse é um lado da moeda, mas existe outro. A grande imagem de liberação sexual oblitera uma realidade sensível: as desigualdades na participação democrática efetiva. Atualmente, o país presencia um embate sociopolítico no qual as bancadas mais conservadoras, afiliadas a grupos religiosos, ganham espaço considerável no Congresso Nacional e na Câmara, elevando seus gritos de protesto contra direitos sexuais outrora conquistados e ameaçando a

\footnotetext{
${ }^{1}$ Texto adaptado da palestra proferida por María Elvira Díaz-Benítez em julho de 2017 na mesa "Sexualidades hoje: provocando desconfortos", na Universidade Federal do Mato Grosso do Sul, debatida pela professora Simone Becker, e escrita originalmente por ambas as autoras que assinam este ensaio.

${ }^{2}$ María Elvira Díaz-Benítez é professora do Programa de Pós-graduação em Antropologia Social do Museu Nacional da Universidade Federal do Rio de Janeiro (PPGAS/MN/UFRJ). Nathalia Ferreira Gonçales é doutoranda do PPGAS/MN e membro do Núcleo de Estudos em Corpos, Gênero e Sexualidade (NuSEX) do mesmo Programa.
} 


\section{Nanduty}

ISSN:2317-8590

laicidade do Estado. Se, por um lado, para o mundo, o Brasil é lugar de eterno verão, produtor de um carnaval lascivo, de corpos e prazeres tropicais e com grande oferta de turismo sexual, por outro, assistimos desconcertados à eleição de pastores para a Presidência da Comissão de Direitos Humanos e Minorias da Câmara, para a Presidência da Câmara Federal, militares de reserva na Câmara de Deputados, líderes pentecostais recebendo títulos de cidadãos beneméritos apesar de sustentarem abertamente opiniões polêmicas sobre homossexuais, negros, direitos das mulheres e, mais recentemente, a respeito dos refugiados.

Todo sexo é político, afirmou a antropóloga estadunidense Gayle Rubin em meados da década de oitenta. O que significa dizer que o sexo é um território, por excelência, utilizado historicamente para as mais diversas disputas de controle, governo, poder e resistências dos corpos, do gênero e das populações. Se todo sexo é político, o labor que esse texto se ocupa em fazer é contribuir com aquilo que Rubin mesma denominou de "uma teoria radical do sexo", ou seja, uma formulação que ajude na criação de um pensamento liberador sobre o sexo, para o qual se deve "identificar, descrever, explicar e denunciar a opressão sexual” (RUBIN, 2017 [1984]: 77). Nesse sentido, esse artigo fará menções a expressões pertencentes ao universo do boxe, uma vez que gênero e sexualidade no Brasil existem dentro de um combate acirrado, sobre vários ringues, e em meio a jabs, knockdowns, crosses, directs, uppercuts, swings, hooks, dribladas, nocautes e pedidos de revanche.

Uma questão todos nós já sabemos: gênero e sexualidade no Brasil não são terrenos neutros. Eles estão envolvidos em relações de poder. Evocam aqueles discursos do começo do século XX sobre raça, mestiçagem e o futuro da nação, métodos eugênicos, criação das patologias e dos pervertidos sexuais. Em poucas palavras, sexualidade e gênero aqui se encontram intimamente ligados aos imaginários coletivos de brasilidade - que foram construídos pela história, medicina, literatura, criminologia, religião, mídia, pornografia - envolvendo questões de classe e de gênero. Não cabe enfatizar o quanto o Brasil é um contexto ótimo para pensar na sexualização da raça e na racialização do sexo, mas vamos cair direto na metáfora do boxe para tentar fazer um apanhado sobre os diversos golpes que têm acontecido nas últimas duas décadas em relação ao gênero e sexualidade. Isso porque apesar de gênero e sexualidade terem ganhado grandes contornos de legitimação no âmbito acadêmico - embora não falte aquele 


\section{Nanduty}

ISSN:2317-8590

antropólogo clássico que acredite que isso não seja antropologia - e os movimentos sociais tenham dado passos gigantes em vias a sua inclusão efetiva, simultaneamente, atravessamos conjunturas que ameaçam social, cultural e politicamente os ganhos conseguidos. Para dar uma ordem a nossa exposição e sabendo que algumas temáticas ficarão de fora, enfatizaremos sobre 1) Aborto, 2) O Programa Brasil sem Homofobia, 3) Os projetos de "Cura Gay”, 4) A Lei João W. Nery para transexuais, 5) A Lei Gabriela Leite e o embate ao redor da legislação da prostituição, 6) A criminalização das vítimas de violência sexual, 7) A ideologia de gênero e sua inclusão nos planos curriculares e 8) o Estatuto da família.

Comecemos por um esboço histórico que nos remete à noção de direitos sexuais, categoria que ganhou contornos de legitimação no começo dos anos 90 e que possibilitou a inclusão da sexualidade na agenda política internacional. Direitos sexuais foi construído como noção no ano de 1994 em função da Conferência Internacional de População e Desenvolvimento realizada no Cairo, e em 1995 ao redor da IV Conferência Mundial sobre a Mulher, realizada em Pequim (cf. MORAES, 1996; GUARNIERI 2010; DIAZ, CABRAL \& SANTOS, 2004; VIANNA \& LACERDA, 2004; MATTAR, 2008). Previamente, no âmbito brasileiro dos anos 1980, já haviam sido iniciadas as interlocuções entre movimentos de mulheres e movimentos feministas com o Estado, abrindo passo ao que se constituiu como sendo as primeiras políticas públicas para mulheres (cf. SARTI, 2004; PONTES, 1986; VIANNA \& LACERDA, 2004; SCHUMAHER, 2005). A década de 1990 assistiu ao fortalecimento de novos atores políticos em relação a processos igualmente políticos em contexto nacional e internacional, instituindo uma agenda brasileira que procurava combater o racismo, a homofobia e as desigualdades de gênero, evocando aquilo que na virada do século se tornariam as ações afirmativas (FACCHINI, ET AL, 2013). A epidemia de HIV/AIDS representou um marco para o fortalecimento de ações em torno da população LGBT, com ênfase no G dessa sigla. Se a saúde seria o interesse primordial em relação a homens que fazem sexo com homens, no caso das mulheres o combate à violência constituiria o mote principal. Outras dimensões dos Direitos Humanos viriam a ser incorporadas aos poucos. A epidemia era uma espécie de dispositivo para a implementação de políticas, e isso apenas foi possível graças à visibilidade que os coletivos LGBT ganhavam no território nacional 


\section{Nanduty}

ISSN:2317-8590

a partir das Paradas de Orgulho e pelo debate público em torno de candidaturas e projetos de Lei (cf. MELLO ET AL, 2012; SIMÕES E FACCHINI, 2009; FACCHINI ET AL, 2013).

Ditas estratégias produziram avanços na arena estatal. Um dos mais relevantes se deu no âmbito Executivo Federal a partir da implementação do programa Brasil sem Homofobia, de 2004, e no projeto de Lei da Câmara 122/2006 que criminaliza a homofobia. Se a AIDS e as questões da saúde foram o mote inicial, logo as agendas se expandiriam no sentido de procurar por garantias mais amplas em outras instâncias de articulação, relativas a direitos humanos. Desde os anos 90, já num período de democratização política, surgiram candidaturas LGBT em vários partidos (cf. SANTOS, 2016). PT e PSTU seriam os principais partidos com ditas candidaturas, mas não os únicos. Foi ainda nessa década que os projetos de lei sobre a união civil entre pessoas do mesmo sexo encontraram lugar. O reconhecimento dos direitos relativos a uniões estáveis ocorrido em 2011 no Supremo Tribunal Federal representou uma das maiores conquistas no âmbito Judiciário: isto é, um jab direto daqueles que fazem o adversário cair no ringue.

O Programa Federal Brasil sem Homofobia foi lançado em 2004 e organizado pela Secretaria de Direitos Humanos da Presidência da República, cujos objetivos eram: "promover a cidadania de gays, lésbicas, travestis, transgêneros e bissexuais, a partir da equiparação de direitos e do combate à violência e à discriminação homofóbicas, respeitando a especificidade de cada um desses grupos populacionais" (BRASIL SEM HOMOFOBIA, 2004: 11). Essa década é fundamental para as construções da agenda LGBT enquanto política pública. Mas contemos um pouco do começo: um importante antecedente teve lugar na Conferência de Durban, em 2001 na África do Sul, na qual o comitê brasileiro propôs que a orientação sexual fosse uma forma de discriminação análoga ao racismo. Essa moção não foi aceita, mas criou bases e, ainda nesse ano, foi fundado o Conselho Nacional de Combate à Discriminação (CNCD) como parte do Ministério da Justiça (MDH, 2001).

Em 2010, por decreto presidencial n $\mathrm{n}^{\mathrm{0}} 7388$, o CNCD passou a ter como nome "Conselho Nacional de Combate à Discriminação e Promoção de Direitos LGBT’. Para chegar até essa realização, a I Conferência Nacional de Gays, Lésbicas, Bissexuais, Travestis e Transexuais em 2008 foi um importante marco para a política LGBT no Brasil, contando com a presença do 


\section{Nanduty}

ISSN:2317-8590

presidente Lula e, em certo aspecto, significando reconhecimento do Estado. Podemos considerar essa conquista como um uppercut dos movimentos sociais que abriu passo para a elaboração do Plano Nacional de Promoção de Cidadania e Direitos Humanos de Lésbicas, Gays, Bissexuais, Travestis e Transexuais, em 2009, e para uma segunda Conferência em 2011 (cf. AGUIÃO, 2014; 2016; AIDAR, 2016).

A referida segunda Conferência já não teve o mesmo tom de celebração, alegria e esperança da primeira, tampouco contou a presença da presidenta Dilma. Ao contrário, esteve marcada pelo obstinado tom de reclamação e insatisfação dos movimentos sociais diante de perceptíveis retrocessos (AGUIÃO ET AL, 2014; SANTOS, 2016): o principal deles, a proibição da divulgação do kit anti-homofobia, um maldito soco no estômago dos movimentos LGBTs, fazendo sangrar uma úlcera gástrica antiga que aos poucos começava a sarar. A partir de 2004 e dentro do Programa Brasil sem Homofobia, firmou-se um acordo com o Fundo Nacional de Desenvolvimento da Educação que consistia na elaboração de um material didático com objetivo de ser distribuído às instituiçõoes do país. Pronto para ser divulgado, uma controvérsia impediu sua circulação: os setores conservadores do Congresso e da sociedade fizeram pressão contra o projeto. De modo pejorativo, chamaram o material de "kit-gay" sendo, segundo eles, responsável por "estimular promiscuidade e homossexualismo" em crianças e adolescentes. O governo cedeu às coações - mais na frente vamos explicar como se construíram ditos constrangimentos. Esse material foi cuidadosamente elaborado durante quatro anos e recebeu investimento de quase dois milhões de reais. Mesmo assim, sua circulação institucional foi proibida, o que não impediu que a Associação Brasileira LGBT o divulgasse gratuitamente nas mídias sociais.

Jair Bolsonaro e vários de seus "sparings" - ou seja, outros fundamentalistas com cadeiras de poder no Congresso e na Câmara - foram importantes para a construção do veto. Bolsonaro denunciava que o mal denominado "kit-gay" seria, na verdade, propiciador de bolsas e cotas com a finalidade de favorecer homossexuais e travestis, causando o desmoronamento da heterossexualidade, a desconfiguração da família tradicional e uma má formação moral para crianças entre seis e doze anos. Em suas palavras: "todo esse material vai para a garotada a partir dos seis anos, ensinando-as a serem homossexuais" (MAISPAJEU, 2014). A coalisão de grupos 


\section{Nanduty}

ISSN:2317-8590

religiosos foi imprescindível, levantando discursos fundamentalistas que têm como efeito a exacerbação de pânicos morais já bem conhecidos na nossa sociedade.

Lembremos do pastor Silas Malafaia, psicólogo de formação que, manifestando-se contrário ao projeto de Lei 122, a lei anti-homofobia, afirmou que ela seria a porta de entrada para a pedofilia (Gonçalves, 2016). Infelizmente, esse tipo de associação livre entre homossexualidade e pedofilia é enormemente aceito por diversos setores de nossa sociedade que veem ali a oportunidade para recusar sujeitos LGBTs e, inclusive, eliminá-los através de ataques violentos que já têm cobrado inúmeras vidas. Malafaia adicionou:

perto de $50 \%$ dos homossexuais foram violados quando crianças ou adolescentes. É provado. Ninguém nasce homossexual. A criança quando nasce tem uma predisposição para herdar características biológicas do sexo que veio. Eu acredito que uma criança deve ser criada por um homem e uma mulher. Eu não estou falando de minha crença, estou falando de civilização humana (FATIMA NEWS, 2014: s/p).

Falemos então da tal "cura gay", uma combinação de jabs diretos, frontal e cruzado sobre o olho esquerdo do corpo LGBT. Citando Gonçalves (Ibid., p. 1):

Em 18 de junho de 2013, a Comissão de Direitos Humanos e Minorias aprovou o Projeto de Decreto Legislativo PDC 24/11, de autoria do então deputado federal e presidente da Frente Parlamentar Evangélica João Campos (PSDB-GO), no qual sustava a aplicação do parágrafo único do art. $3^{\circ}$ e o art. $4^{\circ}$ do Conselho Federal de Psicologia $\mathrm{n}^{\circ} 1$ que estabelece normas de atuação para os psicólogos em relação à questão da orientação sexual.

O projeto foi arquivado em julho de 2013, mas reaberto em abril de 2015 na Comissão de Direitos Humanos e Minorias sob a tutela do pastor e deputado Federal Marcos Feliciano (PCSSP). Sua estratégia foi convocar sujeitos que se apresentavam como ex-homossexuais, após a conversão religiosa e o apoio terapêutico, para oferecer relatos em audiência pública. O requerimento foi aprovado e a audiência pública aconteceu em 24 de junho de 2015, contando com pastores, missionários, deputados, psicólogos e ativistas LGBTs (GONÇALVES, 2016).

Em parceria, o Ministério Exodus Brasil e o Grupo de Amor, Aceitação e Perdão (GAAP) empreendem uma batalha pelo aconselhamento àqueles que lutam pela sua identidade restaurada e desejam voluntariamente abandonar o estilo de vida homossexual (Ibid). Em sua pesquisa de doutorado ainda em andamento, o antropólogo Alexandre Gonçalves tem mapeado dezenove organizações vinculadas ao Exodus e ao GAAP divididas em seis escolas de capacitação, dez 


\section{Nanduty}

ISSN:2317-8590

igrejas e três ministérios. $\mathrm{O}$ autor ressalta em sua análise o quanto os discursos construídos por esses reformistas combinam não apenas narrativas religiosas que fazem alusão ao pecado, mas narrativas políticas - no sentido de ponderar quais práticas devem ou não ser reconhecidas pelo Estado - e narrativas científicas, ou seja, a homossexualidade como distúrbio psicológico possuidor de uma origem específica que pode ser combatida. Nos discursos dos conversos se fazem presentes narrativas sobre pais ausentes, abusos sexuais na infância e outros tipos de traumas que seriam a causa de suas homossexualidades. Fica evidente o conhecimento e uso da teoria freudiana por parte desses agentes, e fica claro também que essas construções discursivas apontam para uma pedagogia da família heterossexual, onde a sexualidade, diria Foucault (2010[1975]), deve ser vigiada, esquadrinhada, enquadrada e seus desvios combatidos. Por ironia, a noção de construcionismo das ciências humanas e dos estudos de gênero e sexualidade como é possível corroborar na pesquisa de Gonçalves - é mobilizada pelos reformistas para afirmar a possibilidade da desconstrução da homossexualidade. Quer dizer, os reformistas estão antenados com as categorias teóricas e estão falando para a população de pensamento progressista através de seus próprios discursos.

Queremos mostrar que, apesar das disputas em torno da homossexualidade nos anos $60 \mathrm{e}$ 70 - levando a sua retirada da lista dos desvios sexuais pela Associação Americana de Psiquiatria em 1973, de Psicologia em 1975, no Brasil em 1985 do Código de Doenças, e logo em 1990 deixando de ser considerada pela Organização Mundial da Saúde (OMS) como um "transtorno sexual" -, gênero e sexualidade permanecem como um território de disputas no qual os desviantes nunca perdem realmente o referido rótulo e que tal condição está suscetível a atualizações constantes. Percorrendo os traçados do sexo e gênero no Brasil, tamanha experiência demonstra que o secularismo está sendo colocado em xeque por meio de uma atuação pública onde os atores religiosos buscam uma influência moral nos âmbitos do Estado, da ciência e do mercado. Estariam esses atores anunciando o fim do secularismo?

Continuemos, então, nosso percurso por outras disputas, desta vez relativas aos direitos das mulheres, especificamente sobre violência e aborto. Em 2003, o governo Lula incentivou alianças sem precedentes com os movimentos feministas. Foi criada a Secretaria Especial de Políticas para as Mulheres (SPM), que visava a produção de políticas públicas específicas para as 


\section{Nanduty}

ISSN:2317-8590

mulheres e para as questões de gênero. Esse foi o patamar que consolidou um espaço público de diálogo para as propostas de conferências nacionais de políticas para as mulheres em julho de 2004, agosto de 2007, dezembro de 2011 (cf. MACHADO 2016), no primeiro mandato da Dilma, e uma quarta programada para maio de 2016, poucos dias após a primeira performance pública do Golpe na Câmara.

A relação entre o governo Lula e a Secretaria Especial de Políticas para as Mulheres possibilitou uma estrutura e articulação de enorme envergadura que viabilizou adesões estaduais e municipais aos Pactos Nacionais, como o Pacto do Enfrentamento à Violência e o Pacto da Redução da Mortalidade Materna (IDEM). A SPM e o Conselho Nacional de Direitos das Mulheres levaram o projeto de Lei de Enfrentamento à Violência Doméstica Contra as Mulheres, aprovado no Legislativo em 2006, conhecida como lei 11340/2006 ou Lei Maria da Penha (SPM, 2016). Este é, sem dúvida, o melhor swing dado pelos movimentos sociais feministas. Swing, para quem não sabe, é o golpe mais potente do boxe. Ele é dado com a mão de trás e lançado de forma descendente, buscando atingir o queixo ou qualquer outra parte do rosto do adversário com a maior potência possível. É um golpe de tudo-ou-nada e, se for efetivado corretamente, configura nocaute.

Nesse bojo, criou-se a Casa da Mulher Brasileira e novas legislações para a interpretação do que seria feminicídio. Foi no governo Lula que a SPM e o CNDM incluíram como diretrizes as temáticas

da autonomia das mulheres e igualdade no mundo do trabalho, educação inclusiva não racista, não homofóbica e não lesbofóbica, saúde das mulheres, direitos sexuais e direitos reprodutivos, enfrentamentos de todas as formas de violência contra as mulheres, gestão e monitoramento do plano (MACHADO, 2016: 15).

No interior da temática dos direitos reprodutivos, estava contido o direito à interrupção da gravidez proposto através das Jornadas pelo Aborto Legal e Seguro que congregava mulheres de várias redes feministas. Lia Zanotta Machado (IDEM) nos lembra que embora a II Conferência de Políticas para as Mulheres, de agosto de 2007, tenha encaminhado o projeto de interrupção da gravidez do Executivo ao Legislativo, essa proposta aprovada não consta no II Plano Nacional de Políticas para as Mulheres de 2008. Percebemos aqui um dos principais pontos de tensão entre os 


\section{Nanduty}

ISSN:2317-8590

movimentos feministas e o Estado em uma conjuntura política que suscitou a ascensão dos conservadorismos.

No momento em que a ministra Nilceia Freire fez movimentações na elaboração da minuta de projeto de Lei para legalizar a interrupção da gravidez via Comissão de Seguridade Social e Família da Câmara dos Deputados, paralelamente, ocorria a denúncia do Mensalão. A autora lembra que essa conjuntura propiciou condições para a troca de moedas políticas, como o apoio da Conferência Nacional dos Bispos do Brasil (CNBB) ao governo, desde que o projeto do aborto fosse retirado ou interrompido em seu prosseguimento. Citando:

com a vulnerabilização do governo federal, se fortaleceram os setores conservadores da igreja católica, foi assinado o novo estatuto da Igreja Católica no Brasil, assim como ganharam espaços de reconhecimento, por analogia, outras religiões e seitas cristãs (MACHADO, 2016: 18).

A legalização do aborto se tornou uma espécie de pedágio através do qual o governo, em troca de alianças, exerceria um modo estatal de controle do corpo das mulheres. Em outubro de 2005, como resposta à proposição da minuta da legalização do aborto, foi registrada a primeira Frente Parlamentar em defesa da vida contra o aborto, e com essa nova legislatura, se formou também a Frente Parlamentar a favor da Família (IDEM: 18). Para 2015, encontramos registradas, ainda, a Frente Parlamentar Mista da Família e Apoio à Vida e a Frente Parlamentar em Defesa da Vida e da Família. Assim, a Comissão de Seguridade Social e Família passa a ser cobiçada pela bancada evangélica multipartidária - criada em setembro de 2003 - que reúne deputados de diferentes ordens associados em um propósito: a defesa da família tradicional e seu ímpeto contra o aborto e os direitos de pessoas LGBTs.

O conservadorismo moral, para 2010, momento da eleição presidencial entre Dilma e Serra, estava em plena ascensão e veio marcar a vulnerabilidade dos candidatos e do governo. Assim, a bancada evangélica multipartidária distribuiu seu apoio tanto a Dilma como a Serra, garantindo que ambos se declarassem contra a legalização do aborto ou que, pelo menos, se comprometessem a não levantar essa bandeira. Novamente, citamos Zanotta Machado (2016: 20):

a legalização do aborto passou a ser temática proibida na presidência de Dilma Roussef. Romperam-se assim a aliança e a coalizão entre os feminismos e o segundo governo Lula e os governos Dilma, no que se refere à proposição de um projeto de Lei que, tal como estava na minuta apresentada à Comissão de Seguridade Social e 


\section{Nanduty}

ISSN:2317-8590

Família, legalizaria o aborto nas 12 primeiras semanas da gestação sem obrigar mulheres a declarar suas razões, e legalizaria o aborto diante de graves malformações fetais ou risco à saúde das mulheres.

Como conclusão, a perpetuação da ilegalidade do aborto constitui o primeiro grande knockdown às movimentações feministas e, desta vez, a combinação de jabs foi dirigida diretamente ao útero. O ápice desse embate contra o aborto se deu em 2013, liderado por Eduardo Cunha, cujo projeto de Lei (CÂMARA DOS DEPUTADOS, 2013) tinha como justificativa afirmar que a legalização do aborto vem sendo imposta de modo global por organizações internacionais inspiradas em uma ideologia neomalthusiana de controle populacional e financiadas por fundações norte-americanas ligadas a interesses capitalistas. Ao ler o projeto de Lei, é possível entender que, segundo ele, lutar contra o aborto é lutar contra as investidas do capitalismo e sua ofensiva internacional contra uma maioria esmagadora do povo brasileiro.

Outro enorme complicador do PL 5069/2013 de Eduardo Cunha é que, em decorrência do mesmo, se dá a criminalização das vítimas de violência sexual. Dito projeto de Lei apresenta brechas que, como bem explicam os movimentos feministas e funcionários de saúde, podem levar à proibição, inclusive, do uso da pílula do dia seguinte. O problema está nos trechos que modificam a Lei 12.845 de 2013, que dispõem sobre o atendimento obrigatório e integral a pessoas em situação de violência sexual. Essa lei diz que, no caso de estupro, a "profilaxia da gravidez é um procedimento de atendimento imediato e obrigatório em todos os hospitais do Sistema Único de Saúde". O termo foi substituído por algo pouco claro: "procedimento ou medicação, não abortivos, com eficiência precoce para prevenir gravidez resultante de estupro".

Como nada é tão suficientemente ruim que não possa piorar, esse projeto de Lei acrescenta um novo artigo: "Nenhum profissional de saúde ou instituição, em nenhum caso, poderá ser obrigado a aconselhar, receitar ou administrar procedimento ou medicamento que considere abortivo". Assim, modificando diversos artigos do Código Penal, o que se visa é tornar crime "induzir ou instigar a gestante a praticar aborto ou ainda lhe prestar qualquer auxílio para que o faça" e "orientar ou instruir a gestante sobre como praticar aborto", exceto nos casos de "gravidez resultante de estupro, constatado em exame de corpo de delito e comunicado à autoridade policial". A pena prevista - detenção de seis meses a dois anos - aumenta quando o 


\section{Nanduty}

ISSN:2317-8590

“crime é cometido por agente de serviço público de saúde ou por quem exerce a profissão de médico, farmacêutico ou enfermeiro". No começo do ano de 2017, a situação do projeto de Lei em questão era: "aguarda inclusão na pauta da Câmara. Esse projeto deve perder densidade, caso Cunha seja afastado. Não tem apoio político suficiente para, sem ele, ser pautado. Depende de alguém muito conservador, mas a tendência é que não passe pelo colégio de líderes da Câmara”. Tremendo engano. Esse sujeito conservador apareceu: Eduardo Moura, do PSC, ainda em 2017 reabriu o processo. Não custa lembrar que Eduardo Moura é investigado no Supremo Tribunal Federal em Inquérito no âmbito da Lava Jato.

No limite, esse tipo de medida acaba por punir a mulher estuprada. Como se o estupro já não fosse uma marca de sofrimento suficiente, o Estado vem para corroborar o sofrimento obrigando-as a terem partos de filhos produtos da violência sexual ou, então, a praticarem abortos inseguros, daqueles que cobram um sem-número de vidas femininas. Institui-se uma forma legalizada e estatal de feminicídio, uma nova eugenia que atinge principalmente as mulheres pobres já que, via de regra, são as mais pauperizadas que solicitam os serviços do SUS.

Vamos falar rapidamente de duas outras leis fundamentais para a inclusão social de sujeitos historicamente excluídos e dos constantes golpes que ambas vêm sofrendo: a Lei João W. Nery ou de Identidade de Gênero e a Lei Gabriela Leite. O movimento social organizado por pessoas trans no Brasil teve início em 1992 com a fundação da Associação de Travestis e Liberados do Rio de Janeiro (ASTRAL), parceria entre travestis e mulheres trans que se prostituíam e lutavam contra a violência policial da qual eram alvo (MELINO, 2015: 93). Em 1993, a ASTRAL organizou no Rio de Janeiro o Primeiro Encontro Nacional de Travestis e Liberados com noventa e cinco participantes de cinco estados diferentes. Foi apenas em 1995, com a criação da Associação Brasileira de Gays, Lésbicas e Travestis, que o $\mathrm{T}$ entrou efetivamente na sigla oficial (ABGLT). No ano 2000, se concretiza a expansão da letra T para travestis e transexuais em meio à criação da Articulação Nacional de Travestis, Transexuais e Transgêneros (ANTRA). ${ }^{3}$ Melino (IDEM) lembra que foi somente no final de 1990 e início dos

\footnotetext{
${ }^{3}$ Ver: https://antrabrasil.org/historia/. Sobre este percurso, recomendamos ler os trabalhos da advogada Heloisa Melino (2015), dos antropólogos Mario Carvalho e Sergio Carrara (2013) e do também antropólogo Bruno Cesar Barbosa (2015)
} 


\section{Nanduty}

ISSN:2317-8590

anos 2000 que começou a se falar de identidade de gênero nos movimentos sociais LGBTs, questão que surgiu dentro do debate sobre transexualidade.

O projeto de Lei leva o nome de João W. Nery em homenagem ao primeiro homem transexual operado no Brasil, ainda em 1977, em plena ditadura militar. João, psicólogo, teve seu registro cassado pelo Conselho Nacional de Psicologia quando passou a atender com seu nome social sob alegação de que estaria cometendo falsidade ideológica. ${ }^{4}$ A lei leva seu nome como símbolo de resistência e como exemplo das dificuldades que a comunidade trans enfrenta por conta dos entraves institucionais ao reconhecimento de suas identidades (MELINO, 2015: 96). O projeto de Lei foi apresentado em 2013 pelos deputados Jean Wyllys, do PSOL-RJ, e Érika Kokay, do PT-DF, e se baseia na lei argentina de identidade de gênero, reconhecida como a mais avançada do mundo. No artigo $2^{\circ}$ do projeto, aparece a seguinte definição: "Entende-se por identidade de gênero a vivência interna e individual do gênero tal como cada pessoa o sente, a qual pode corresponder ou não com o sexo atribuído após o nascimento, incluindo a vivência pessoal do corpo". A lei procura o reconhecimento pelo Estado como primeiro passo para atingir uma segurança jurídica, de modo a que as políticas públicas formuladas para a população trans não sejam meras concessões.

Sobre as enormes peregrinações institucionais das pessoas trans para conseguir os documentos de mudança de sexo, vale a pena ler a dissertação de Lucas Freire, defendida no Programa de Pós-graduação em Antropologia Social do Museu Nacional em 2015; já o teor completo do referido projeto de Lei encontra-se facilmente na Internet (CÂMARA DOS DEPUTADOS, 2013b). De fato, do momento em que esta fala foi proferida até a presente publicação do texto, uma retumbante vitória foi celebrada em março de 2018 com a aprovação no Supremo Tribunal Federal do direito à modificação de nome e gênero no registro civil independente de qualquer procedimento cirúrgico de redesignação de sexo. Apesar dos constantes obstáculos interpostos por diversas forças conservadores, tal decisão afirmativa da Suprema Corte garantiu o projeto de Lei João W. Nery (5002/2013), que há cinco anos tramitava na Câmara, abrindo um precedente no exercício de direito à identidade de gênero para as pessoas

\footnotetext{
${ }^{4}$ Sobre João W. Nery, ler seu livro Viagem Solitária - Memórias de um Transexual Trinta Anos Depois (2011), Editora Leya.
} 


\section{Nanduty}

ISSN:2317-8590

trans que não dispõem de recursos para intervenções cirúrgicas ou que simplesmente não desejam realizá-las.

No entanto, ainda há muito que lutar para que as demandas da população trans alcancem uma instância propriamente energética. De acordo com o deputado federal Jean Wyllys - um dos autores da Lei João W. Nery -, o Supremo ainda não deliberou sobre "o acesso à hormonoterapia, às cirurgias de redesignação através do SUS, verbas para educação e cultura e a criação de um programa nacional que estude e planeje ações para reduzir o preconceito contra as pessoas trans" - medidas também previstas na proposição da nova lei. Nesse sentido, as palavras de Indianara Siqueira ${ }^{5}$ recobram importância: "para nós, Stonewall é todos os dias". A batalha das pessoas trans é travada cotidianamente com suas famílias, com as escolas, com a sociedade, com a polícia e com o Estado.

De família humilde, a travesti Dandara dos Santos trabalhava vendendo roupas de segunda mão e colaborava com sua mãe nas tarefas domésticas. No dia 15 de fevereiro de 2017, no bairro de Bom Jardim, Fortaleza, Dandada foi brutalmente espancada com pedradas, pauladas, chutes e executada a tiros por um grupo de homens. O crime alcançou repercussão internacional após a divulgação de imagens do linchamento registradas por um dos participantes, que publicou o vídeo na internet. Tais imagens foram usadas pela polícia e pelo Ministério Público como provas suficientemente abundantes do crime, sendo decisivas na identificação dos culpados e na penalização individualizada da sentença de acordo com a participação de cada réu.

O juiz entendeu que os cinco acusados pela morte de Dandara agiram por motivo torpe, com agravante de crueldade e sem chance de defesa para a vítima. Foram condenados a penas que variam de 14 a 21 anos de prisão em regime fechado. A qualificação pela motivação transfóbica fez do julgamento um caso emblemático dentro de um universo de vulnerabilidade no qual grande parte dos homicídios sequer chega a ser investigada pela polícia. Apesar da rápida resolução no caso de Dandara, as vidas trans no Brasil sofrem constantes ameaças a sua

\footnotetext{
${ }^{5}$ Conhecida Ativista Trans e pelos direitos das prostitutas. Líder e coordenadora da Casa NEM. Idealizadora do projeto Prepara, Nem, cuja proposta é a preparação de pessoas trans e travestis para o ENEM. Vereadora suplente do PSOL.
} 


\section{Nanduty}

ISSN:2317-8590

integridade, sendo o país que possui o maior número de assassinatos de pessoas trans, segundo a ONG Transgender Europe. ${ }^{6}$

É importante lembrar que ainda não há tipificação para crimes de homofobia, lesbofobia ou transfobia - resultantes da discriminação por orientação sexual ou identidade de gênero -, como existe atualmente com os homicídios dolosos, não necessariamente consumados, perpetrados contra uma mulher em razão da sua "condição do sexo feminino", 7 a isto especificase feminicídio no código penal. Em uma manobra discursiva estratégica, a definição estabelecida por lei do que é ser mulher, no intuito de qualificar um crime como feminicídio, deixa brechas problemáticas na formulação de um modelo binário que associa rigorosamente sexo anatômico à identidade de gênero. Essa dobra permite ocultar inúmeras violências de gênero sofridas por mulheres que têm sua identidade de gênero negada em função de uma suposta inadequação biológica.

Cabe mencionar que a história do movimento trans se encontra, em variados momentos, conectada com a história do movimento a favor da prostituição e é sobre isso que vamos falar agora. Muito resumidamente, comentamos que o movimento conhecido como Rede Brasileira de Prostituição nasceu na luta contra a violência policial perpetuada por setores da sociedade civil no exercício da atividade. Vale lembrar que a atividade consta como legal e reconhecida pelo Ministério de Trabalho e do Emprego (MTE), presente no código brasileiro de ocupações número 5.198-05, sendo categorizada como "profissionais do sexo". Contudo, a rede em volta da prostituição permanece ilegal, tal como o agenciamento e a manutenção de casas para prostituição. O código penal tipifica os crimes de agenciamento de prostitutas - mediação para servir a lascívia de outrem, se não receber nada em troca, e rufianismo se houver contra-prestação pelo trabalho de agenciamento - e de manutenção de casas de prostituição. Artigos 227, 228, 229 e 230 .

\footnotetext{
${ }^{6}$ In 2012, Transgender Europe published "TRANSRESPECT VERSUS TRANSPHOBIA WORLDWIDE - A Comparative Review of the Human-rights Situation of Gender-variant/Trans People", which contextualises the TMM data (TRANSRESPECT, 2012).

${ }^{7}$ Trecho da Lei 13.104 de 9 de março de 2015, o art. 121, § 2 do Código Penal.
} 


\section{Nanduty}

ISSN:2317-8590

A disputa do movimento de prostitutas diante dessa lei se dá em função da existência de diversos casos em que a aplicação da lei é usada para criminalizar as próprias prostitutas. Reclamam que tal enquadramento penal não é tão simples, indicando que, muitas vezes, agenciar prostitutas ou abrir uma casa para o exercício da atividade não significa, necessariamente, explorar pessoas através da prostituição. Assim, torna-se urgente definir o que é agenciamento e o que é exploração, estabelecendo limites entre a atividade legal e necessária e a atividade ilegal e exploratória. Como diz Melino (2015: 103):

Assim como atores, modelos, atrizes, lutadores de boxe, de vale tudo ou de luta livre têm agentes, prostitutas muitas vezes também tem e essa mediação pode facilitar o trabalho e garantir maior segurança. A ilegalidade generalizada, associada à marginalização social deixa às prostitutas em extrema vulnerabilidade.

No cenário de lutas das prostitutas, as demandas por direitos humanos e trabalhistas têm ganhado prioridade através do entendimento de que são fundamentais para a garantia da cidadania e melhoria da qualidade de vida, inclusive de segurança, dessas profissionais. Esse é o foco do projeto de Lei Gabriela Leite, de autoria dos movimentos sociais e apresentado pelo deputado federal Jean Wyllys (CÂMARA DOS DEPUTADOS, 2012). Trata-se de um projeto que tem gerado extenso debate entre conservadores e progressistas e, inclusive, dentro dos próprios feminismos. A reclamação contida no projeto de Lei Gabriela Leite consiste em limpar a constante confusão gerada pela redação da atual lei, na qual exploração sexual e prostituição se confundem. O capítulo V, por exemplo, “do lenocínio e do tráfico de pessoa para fim de prostituição ou outra forma de exploração sexual":

Art 228 do Código Penal: Induzir ou atrair alguém à prostituição ou outra forma de exploração sexual

Art. 231. Promover ou facilitar a entrada, no território nacional, de alguém que nele venha a exercer a prostituição ou outra forma de exploração sexual.

A redação "prostituição ou outra forma de exploração sexual" dá margem a entender que a prostituição é, de fato, uma forma de "exploração sexual". Sendo a prostituição uma ocupação registrada no Ministério do Trabalho e do Emprego, entende-se que ela é exercida por pessoas maiores de idade. Não existe, portanto, prostituição de crianças e adolescentes. Nesses casos, a prática se configura como exploração sexual. Essa confusão dos termos reforça o estigma sobre 


\section{Nanduty}

ISSN:2317-8590

as prostitutas e dimensiona efeitos diretos desse estigma sobre corpos de carne e osso. O projeto Gabriela Leite propõe uma mudança na redação, definindo em seus parágrafos I e II com precisão quem exerce a prostituição e o que se tipifica como exploração sexual. O projeto de Lei luta também, como já dito, pela descriminalização das atividades entorno da prostituição: o agenciamento, associação por cooperativas ou manutenção de casas. O que está em jogo é a desmarginalização da prostituição, ou como diz Jean Wyllys na justificativa do projeto:

O objetivo principal do presente projeto de Lei não é só desmarginalizar a profissão, mas com isso, permitir aos profissionais do sexo, acesso à saúde, ao direito do Trabalho, à segurança pública e, principalmente, à dignidade humana. Mais que isso, a regularização da profissão do sexo constitui um instrumento eficaz ao controle da exploração sexual, pois possibilitará a fiscalização em casas de prostituição e o controle do Estado sobre o serviço (CÂMARA DOS DEPUTADOS, 2013b: s/p).

O enorme agravante desta disputa em torno da prostituição é a organização e atuação reacionária de um grupo de pessoas, várias delas feministas, detratoras das causas das prostitutas e defensoras de ideias abolicionistas. Conhecidas como radfems ou radicais, essas feministas vêm propondo uma lei que criminalize a compra de qualquer ato sexual, toda forma de fiscalização do agenciamento e campanhas para a abolição total da prostituição, já que ela perpetuaria relações de exploração machista/patriarcais. O engraçado disso tudo, se é que pode haver algo de espirituoso em questão, é o uso da noção de patriarcado sem nenhum tipo de visão crítica. Patriarcalismo, dependendo de seu uso, pode ser uma ideia vazia ou carente de um sentido preciso. Quais são as formas que o patriarcado assume, como, onde e em que momentos? Quer dizer, não se trata de manifestar que existe de fato um poder patriarcal, senão de caracterizar quais, como, e onde se dão essas relações patriarcais. Isso porque, às vezes, quem exerce o poder patriarcal não é um homem branco, cis, hétero de classe média, senão nossa melhor amiga, nosso namorado ou nossa professora favorita. Atrevemo-nos a dizer que o embate entre as feministas abolicionistas e o movimento de prostitutas está demonstrando, por parte das primeiras, uma impossibilidade para pensar soluções concretas dentro de realidades específicas e, ainda, criando noções abstratas sobre patriarcalismo ao esquecer que essa categoria pode ser exercida por meio de ideias extremas mesmo quando são feitas com "boas intenções”. Sem dizer que estão negando a importante dimensão da agência dos sujeitos. Como diz Indianara Siqueira: "Sinceramente, nós 


\section{Nanduty}

ISSN:2317-8590

putas não temos culpa porra nenhuma da exploração da mulher na sociedade patriarcal e machista. A culpa é da sociedade patriarcal e machista. Quem disse que se acabam as putas acaba o patriarcado?". 8 Em outros termos, se abolicionistas e reformistas acreditam que a causa da prostituição é a pobreza, então porque não estão combatendo a pobreza? ${ }^{9}$

As prostitutas são, sem dúvida, aqueles corpos que vivem dentro de um ringue, sofrem knockdowns o tempo todo, mas ainda assim se levantam, limpam o rosto, driblam e devolvem o soco. A questão é que além de enfrentar as radicais, sofrem investidas do poder legislativo. Atualmente, dois projetos que cerceiam os direitos das prostitutas estão em tramitação no Congresso. Um deles é o projeto de Lei 377/2011, de autoria do deputado João Campos, do PRB, mesmo autor do projeto sobre a "cura gay". Esse projeto busca criminalizar os clientes, prevendo pena de prisão para aqueles que pagarem por serviços sexuais. E o deputado Flavinho, do PSB, indicou o projeto de Lei (INC 2371/2016) cujo objetivo é a retirada do artigo que reconhece as atividades da/o profissional do sexo no Código Brasileiro de Ocupações (CBO).

Para terminar, queremos apenas mencionar os atuais embates ao redor do conceito de gênero e sua exclusão dos planos curriculares nacionais, assim como do denominado Estatuto da Família. A educação pela igualdade de gênero, a educação não sexista, não homofóbica e não lesbofóbica é agenda que os feminismos vêm defendendo desde os primórdios de suas relações com o Estado e que por meio da SPM foi levado a sério nos governos do PT entre 2005 e 2013, através do Programa de Educação de Gênero e Diversidade Sexual. O primeiro jab em relação a essas preocupações já foi mencionado com a retirada de circulação do kit anti-homofobia. No entanto, um enorme jab direto foi recebido em 2015: a retirada pelo Congresso Nacional dos objetivos de enfrentamento à desigualdade de gênero do Plano Nacional de Educação. A pressão do Legislativo é contra o uso do conceito de gênero nas escolas. As relações entre a luta em oposição ao conceito de gênero e o projeto de Escola sem Partido são mais do que óbvias. Cabe repetir que a terminologia de gênero, do modo como é entendida pelo requerimento, é vista como

\footnotetext{
8 Fala de Indianara Siqueira no evento "Identidade de gênero e luta de classes", disponível em: https://www.youtube.com/watch?v=fVgUft40qCU

9 Sobre a discussão entre prostituição e pobreza, ver: Sex Workers Open University (SWOU) "A pobreza é objetificante, degradante e punitiva", em Mundo Invisível, 2015.
} 


\section{Nanduty}

ISSN:2317-8590

danosa para o sistema educacional. No entanto, nós sabemos muito bem que a retirada do conceito procura, no limite, a permanência do regime heterossexual e dos papéis sexuais e de gênero normativos. Sua exclusão é péssima notícia na luta de combate à violência contra as mulheres e pessoas LGBTs, ao machismo e às dinâmicas sociais que vêm sendo chamadas de “cultura do estupro". É ali, nessas escolas, onde os reformistas não querem que a educação de gênero exista, onde se fazem presentes perversas discriminações homofóbicas, estupros coletivos e pornografia de vingança, entre outras violências e humilhações. O Estatuto da Família é uma forma estatal de regulamentação de gênero que, como Judith Butler (2012) diz, existe através da prescrição e reiteração contínua de comportamentos, gestos, falas, atos e discursos fundados numa matriz heterossexual, uma vez que o gênero precisa e institui seu próprio regime de inteligibilidade. Gênero é o aparato através do qual tem lugar a produção e normalização do masculino e do feminino.

Por isso a importância para os reformadores da moral da restauração do Estatuto da Família, cujo combate mais aguerrido teve lugar no dia 24 de setembro de 2015, quando a Comissão Especial sobre o Estatuto da Família, o PL 6.583/13, aprovou por 17 votos a 5 o parecer do relator, o deputado Diego Garcia. De autoria do deputado evangélico Anderson Ferreira, do PP-PE, o texto principal define como família a união entre homem e mulher, e exclui a união homoafetiva de direitos já conquistados como herança, guarda dos filhos e inclusão do(a) parceiro(a) em planos de saúde, entre outros. Ainda, o Estatuto retiraria direitos de outras pessoas cuja composição familiar não é a de união entre homem e mulher, como homens e mulheres sem cônjuge, excluindo diversos arranjos familiares, não apenas a família homoafetiva. Hoje o processo se encontra na mesa diretora da Câmara dos Deputados. Caso ele passe, seria um nocaute indiscutível. ${ }^{10}$

No Rio de Janeiro, sofremos uma perda irreparável na luta pelos direitos das mulheres, LGBTs e da população negra e favelada da cidade: o assassinato orquestrado da vereadora do PSOL Marielle Franco, executada a tiros na noite do dia 14 de março de 2018, junto com o

\footnotetext{
${ }^{10}$ Sobre ideologia de gênero e Estatuto da Família, ler o recente artigo da professora Naara Luna, intitulado: "A criminalização da 'ideologia de gênero': uma análise do debate sobre diversidade sexual na Câmara dos Deputados em 2015".
} 


\section{Nanduty}

ISSN:2317-8590

motorista Anderson Gomes, quando saía do evento "Jovens Negras Movendo as Estruturas". O seu assassinato foi uma tentativa de calar a voz e frear politicamente a construção de uma sociedade com menos ódio e violência. Na contramão do jogo, nessa pancada brutal e sem mediação, padeceu antes quem desferiu o golpe. Entre perplexidade e indignação, a memória de Marielle se tornou um símbolo nacional de luta nas constantes batalhas em defesa das múltiplas formas de vida. Nos 50 dias completos de sua morte, a Câmara dos Vereadores do Rio de Janeiro aprovou cinco projetos de sua autoria apresentados ao plenário pelo PSOL. Os projetos aprovados foram: Espaço Coruja (PL 17/2017), que cria um programa de acolhimento no período noturno às crianças que têm mães que estudam ou trabalham; a inclusão do Dia de Tereza de Benguela em 25 de julho, já reconhecido como Dia da Mulher Negra (PL 103/2017); o Dossiê Mulher Carioca (PL 555/2017), que cria periodicamente um compilado de dados sobre a violência contra a mulher a partir de dados de atendimento do sistema municipal; Assédio não é passageiro (417/2017), que Cria a Campanha Permanente de Conscientização e Enfrentamento ao Assédio e Violência Sexual no município, em espaços públicos e transportes coletivos; e o cumprimento de medida socioeducativa em liberdade (PL 515/2017) com a possibilidade de inserção desse jovem no mercado de trabalho. ${ }^{11}$

Em oposição à investida conservadora ou justamente como resposta a ela, tem se originado uma enorme movimentação de resistência: redes organizadas de movimentos sociais diversos, parcerias entre lideranças dos movimentos feministas com o movimento negro e LGBT, assim como parcerias entre os movimentos e juristas, educadores, cientistas, sindicatos e diversas pessoas da sociedade civil. Há também uma proliferação de novas gerações de jovens feministas. A impressionante quantidade de meninas marchando nas ruas contra as violências de gênero é evidência pulsante dessas novas forças de atuação. Se o gigante conservador acordou, as

\footnotetext{
${ }^{11}$ Menos de dois meses depois do assassinato de Marielle Franco, a estudante Matheusa Passareli foi assassinada no Rio de Janeiro. Inicialmente desaparecida, a polícia encerrou as buscas determinando que seu corpo fora executado e em seguida queimado em uma favela da zona norte da cidade. Matheusa era não-binária, negra e migrante do interior rumo à capital para estudar na Universidade Estadual do Rio de Janeiro, sendo a primeira geração da sua família a acessar uma graduação. Matheusa também frequentava cursos livres de artes visuais no Parque Lage, instituição que recentemente acolheu a exposição Queermuseu, censurada no Rio Grande do Sul ano passado após protestos de grupos conservadores que a acusavam de promover pedofilia, zoofilia e blasfêmia. No encerramento da mostra na zona sul carioca, uma intervenção com pichações realizadas por Gabe Passareli, irmã de Matheusa, permitia ao público ler através dos muros brancos da instituição: "Farsa, apropriação, fogo nos racistas", "Vidas LGBT+ importam".
} 


\section{Nanduty}

ISSN:2317-8590

resistências também estão fazendo sua parte. Para cada Malafaia, Feliciano, Bolsonaro e Cunha da vida, há uma contestação valente de uma mulher, uma trans, uma bicha, uma lésbica ou um cidadão comprometido que reprova as suas ações.

Fechamos a revisão deste ensaio no domingo 22 de setembro de 2018, mais de um ano após a fala que o originou e sem a possibilidade de ter realizado todas as atualizações possíveis. Mas, especialmente, a sete dias do Ato do dia 29, que acontecerá simultaneamente em diversas cidades do país e mundo afora, em função da adesão ao slogan \#EleNão \#EleNunca. Convocado por um grupo que rapidamente reuniu mais de dois milhões de mulheres aproveitando a força das redes sociais, a este se somaram Negros, LGBT, Quilombolas, Professores, Transexuais, entre outros sujeitos e coletivos, aderindo ao mesmo propósito: lutar contra o presidenciável Jair Bolsonaro, conhecido por seus depoimentos misóginos, machistas, homofóbicos, racistas, fascistas, armamentistas e de apologia à tortura, apenas para mencionar o pior de sua pessoa que cabe na temática desse texto. A força do movimento em torno do \#EleNão nos últimos minutos do campeonato abre uma luz de esperança. Constatar a força da resistência frente à onda de conservadorismo no Brasil atual nos permite vislumbrar um melhor futuro possível. Quais serão os desdobramentos para o país? Saberemos muito em breve. A ameaça está colocada e não apenas em termos de gênero e sexualidade. Estamos, literalmente, dentro do ringue, lutando para não sermos aqueles que levam o nocaute.

\section{Referências bibliográficas}

AGUIAO, Silvia. 2016. "Não somos um simples conjunto de letrinhas": disputas internas e (re)arranjos da política "LGBT". In Cadernos Pagu (46), janeiro-abril. Disponível em: http://www.scielo.br/scielo.php?pid=S010483332016000100279\&script=sci_abstract\&tlng=pt Acesso em 22 de setembro de 2018.

2014. Fazer-se no "Estado": uma etnografia sobre o processo de constituição dos "LGBT" como sujeitos de direitos no Brasil contemporâneo. Tese de Doutorado em Ciências Sociais. Universidade Estadual de Campinas. Disponível em: http://www.repositorio.unicamp.br/handle/REPOSIP/281317 Acesso em 22 de setembro de 2018. 


\section{Nanduty}

ISSN:2317-8590

VIANNA, Adriana \& GUTERRES, Anelise. 2014. "Limites, espaços e estratégias de participação do Movimento LGBT nas Políticas governamentais". In LEITE LOPES, José Sérgio e HEREDIA, Beatriz. Movimentos sociais e esfera pública. Rio de Janeiro: CBAE, p. 237-268. Disponível em: http://www.ipea.gov.br/participacao/images/pdfs/2014\%20-

$\% 20$ movimentos\%20sociais\%20-\%20seminario\%20participacao.pdf Acesso em 22 de setembro de 2018.

AIDAR, Adriana Marques. 2016. O Conselho Nacional de Combate à Discriminação e Promoção de Direitos de Lésbicas, Gays, Bissexuais, Travestis e Transexuais (CNCD/LGBT): entraves e possibilidades de participação na elaboração e implementação de políticas públicas. (Tese em Sociologia) na Universidade do Estado do Rio de Janeiro. Disponível em: http://www.iesp.uerj.br/wpcontent/uploads/2017/06/Tese_Adriana-Marques-Aidar.pdf Acesso em 22 de setembro de 2018.

BARBOSA, Bruno Cesar. 2015. Imaginando trans: saberes e ativismos em torno das regulações das transformações corporais do sexo. Tese de Doutorado em Antropologia Social. Universidade de São Paulo. Disponível em: http://www.teses.usp.br/teses/disponiveis/8/8134/tde-09092015-173956/pt-br.php Acesso em 22 de setembro de 2018.

BRASIL SEM HOMOFOBIA. 2004. Programa de Combate à Violência e à Discriminação contra GLTB e de Promoção da Cidadania Homossexual. Disponível em: http://bvsms.saude.gov.br/bvs/publicacoes/brasil_sem_homofobia.pdf. Acesso em 23 de Setembro de 2018.

BUTLER, Judith. 2012. Problemas de Gênero: feminismo e subversão da identidade. Rio de Janeiro: Civilização Brasileira.

CÂMARA DOS DEPUTADOS. 2012. Projeto de Lei Gabriela Leite. Disponível em https://www.camara.gov.br/proposicoesWeb/prop_mostrarintegra?codteor=1012829. Acesso em 22 de setembro de 2018.

CÂMARA DOS DEPUTADOS. 2013. Projeto de Lei que insere o artigo 127-A no Código Penal Brasileiro. Disponível em: http://www.camara.gov.br/proposicoesWeb/prop_mostrarintegra?codteor=1061163. Acesso em 22 de setembro de 2018.

CÂMARA DOS DEPUTADOS. 2013b. Projeto de Lei João W. Nery . Disponível em: http://www.camara.gov.br/proposicoesWeb/prop_mostrarintegra?codteor=1059446. Acesso em 22 de setembro de 2018. 
CARVALHO, Mario; CARRARA, Sérgio. 2013. "Em direito a um futuro trans?: contribuição para a história do movimento de travestis e transexuais no Brasil". In Sexualidad, Salud y Sociedad. (Rio J.) [online], n.14, pp.319-351. Disponível em: http://www.scielo.br/pdf/sess/n14/a15n14.pdf. Acesso em 22 de setembro de 2018.

CARVALHO, Mario e SÍVORI, Horacio. 2017. "Ensino religioso, gênero e sexualidade na política educacional brasileira". In Cadernos Pagu (50). Disponível em: http://www.scielo.br/pdf/cpa/n50/1809-4449-cpa-18094449201700500017.pdf. Acesso em 22 de setembro de 2018

DÍAZ-BENÍTEZ, María Elvira e VIANNA, Adriana. 2016. "Gênero e sexualidade: estamos no canto do ringue?". In Cadernos de Campo, São Paulo, n. 25, pp. 36-41. Disponível em: https://www.revistas.usp.br/cadernosdecampo/article/download/138783/134133. Acesso em 22 de setembro de 2018.

2013. "Posições Políticas". In Dossiê Sexo e poder no Brasil. Revista de Historia da Biblioteca Nacional.

DÍAZ, Margarita; CABRAL, Francisco \& SANTOS, Leandro. 2004. "Os direitos sexuais e reprodutivos". In: RIBEIRO, C.; CAMPUS, M.T.A. (ed.). A final, que paz queremos? Lavras: Editora UFLA, $\mathrm{p}$ 45-70. Disponível em: http://www.reprolatina.institucional.ws/site/respositorio/materiais_apoio/textos_de_apoio/ Os_direitos_sexuais_e_direitos_reprodutivos.pdf. Acesso em 22 de setembro de 2018.

FACCHINI, Regina; DANILIAUSKAS, Marcelo \& PILÓN, Claudia. 2013. "Políticas sexuais e reprodução de conhecimento no Brasil: situando estudos sobre sexualidades e suas conexões”. In Revista de Ciências Sociais, Fortaleza, v. 44, n. 1, jan/jun, p. 161-193. Disponível em: http://www.rcs.ufc.br/edicoes/v44n1/rcs_v44n1a7.pdf. Acesso em 22 de setembro de 2018.

FATIMA NEWS. 2014. Declarações do pastor Silas Malafaia sobre homossexuais. Disponível em: http://www.fatimanews.com.br/cidades/silas-malafaia-50-dos-homossexuais-foramviolados-quando-eram-criancas/161877/. Acesso em 23 de setembro de 2018.

FREIRE, Lucas. 2015. A Máquina da Cidadania: uma etnografia sobre a requalificação civil de pessoas transexuais. Dissertação de mestrado em Antropologia Social. Programa de Pósgraduação em Antropologia Social do Museu Nacional da Universidade Federal do Rio de Janeiro. Disponível

em: https://www.academia.edu/11873996/A_M\%C3\%A1quina_da_Cidadania_uma_etnografi a_sobre_a_requalifica\%C3\%A7\%C3\%A3o_civil_de_pessoas_transexuais. Acesso em 22 de setembro de 2018. 
FOUCAULT, Michel. 2010. A história da sexualidade, vol 1. (Tradução de Maria Thereza da Costa Albuquerque e J.A Gilhon Albuquerque). São Paulo: Graal.

GONÇALES, Nathalia Ferreira. 2017. Das ruínas do corpo sudaca: Experiências póspornográficas na América Latina. Dissertação em Antropologia Social. Programa de Pósgraduação em Antropologia Social do Museu Nacional da Universidade Federal do Rio de Janeiro.

GONÇALVES Alexandre. 2016. "Cura Gay” - articulações entre Ciência e Política na produção de saberes religiosos. Anais do $40^{\circ}$ Encontro Nacional da Anpocs. Caxambu. Disponível em: http://www.anpocs.com/index.php/encontros/papers/40-encontro-anual-da-anpocs/st10/st29-3/10445-cura-gay-articulacoes-entre-ciencia-e-politica-na-producao-de-saberesreligiosos/file. Acesso em 22 de setembro de 2018

GUARNIERI, Tathiana Haddad. 2010. "Os Direitos das Mulheres no contexto internacional - Da criação da ONU (1945) à Conferência de Beijing (1995)". In Revista Eletrônica da Faculdade Metodista Granbery (Curso de Direito), N. 8, Janeiro-junho. 2010. (ISSN 1981 0377). Disponível em: http://docplayer.com.br/1416201-Os-direitos-das-mulheres-nocontexto-internacional-da-criacao-da-onu-1945-a-conferencia-de-beijing-1995-tathianahaddad-guarnieri-1.html. Acesso em 22 de setembro de 2018

LUNA, Naara. 2017. "A criminalização da "ideologia de gênero": uma análise do debate sobre diversidade sexual na Câmara dos Deputados em 2015". In Cadernos Pagu (50), Campinas, Dec 18. Disponível em: http://www.scielo.br/pdf/cpa/n50/1809-4449-cpa18094449201700500018.pdf. Acesso em 22 de setembro

MATTAR, Laura Davis. 2008. "Reconhecimento jurídico dos Direitos Sexuais - Uma análise comparativa com os direitos reprodutivos”. In Sur. Revista Internacional de Direitos Humanos. Ano 5, $\mathrm{n}^{\mathrm{o}}$. 8, São Paulo, junho de 2008. Disponível em: http://www.scielo.br/scielo.php?script=sci_arttext\&pid=S1806-64452008000100004.

Acesso em 22 de setembro de 2018

MDH. 2001. Medida provisória 2216 de 2001 que institui o CNCD-LGBT. Disponível em: http://www.mdh.gov.br/informacao-ao-cidadao/participacao-social/old/cncd-lgbt/cndclgbt. Acesso em 22 de setembro de 18.

MELLO, Luiz; BRITO, Walderes; MAROJA, Daniela. 2012. "Políticas públicas para a população LGBT no Brasil: notas sobre alcances e possibilidades". Cadernos Pagu, (39), pp. 403-429. Disponível em: http://www.scielo.br/pdf/cpa/n39/14.pdf. Acesso em 22 de setembro de 2018.

MORAES, Maria Lygia Quartim de. 1996. 20 anos de feminismo no Brasil. (Tese de livre docência). Departamento de sociologia o Instituto de Filosofia e Ciências Humanas da 
Universidade Estadual de Campinas. Disponível em: https://jpsolce.files.wordpress.com/2012/11/tese-vinte-anos-de-feminismo-maria-lygiaquartim-de-moraes.pdf. Acesso em 22 de setembro de 2018.

MACHADO, Lia Zanotta. 2014. "Interfaces e deslocamentos: feminismos, direitos, sexualidades e antropologia”. In Cadernos Pagu, (42), janeiro-junho de 2014, pp.13-46. Disponível em: http://www.scielo.br/pdf/cpa/n42/0104-8333-cpa-42-00013.pdf. Acesso em 22 de setembro de 2018.

. 2016. "Feminismos brasileiros nas relações com o Estado. Contextos e incertezas". In Cadernos Pagu (47). Disponível em: http://www.scielo.br/pdf/cpa/n47/1809-4449-cpa-18094449201600470001.pdf. Acesso em 22 de setembro de 2018.

2017. "O aborto como direito e o aborto como crime: o retrocesso neoconservador". In Cadernos Pagu (50). Disponível em: http://www.scielo.br/pdf/cpa/n50/1809-4449-cpa-18094449201700500004.pdf. Acesso em 22 de setembro de 2018.

MAISPAJEU. 2014. Jair Bolsonaro em relação ao "kit gay". Disponível em: http://www.maispajeu.com.br/2014/04/kit-gay-volta-com-forca-total-sao.html. Acesso em 22 de setembro de 2018.

MELINO, Heloisa. 2015. Direito, linguagens e emancipação: Processos de luta e o potencial transformador dos movimentos sociais. Dissertação de Mestrado em Direito. Universidade Federal do Rio de Janeiro.

MUNDO INVISÍVEL. 2015. Disponível em: http://www.mundoinvisivel.org/a-pobreza-eobjetificante-degradante-e-punitiva/. Acesso em 22 de setembro de 2018.

NERY, João W. Viagem Solitária. Memórias de um transexual Trinta Anos Depois. São Paulo: Editora Leya. 2011.

OLIVEIRA, Esmael Alves de \& DUQUE, Thiago. "Políticas do corpo, políticas da vida: uma análise sobre o estatuto da família no Brasil". In Revista Nanduty, v.4 n 5, 2016. Disponível em: http://ojs.ufgd.edu.br/index.php/nanduty/article/view/5759/2929. Acessado em 22 de setembro de 2018.

PONTES, Heloisa. 1986. Do palco aos bastidores: o SOS Mulher e as práticas feministas contemporâneas. Dissertação em Antropologia) - Universidade Estadual de Campinas, Campinas, SP. Disponível em: http://repositorio.unicamp.br/jspui/handle/REPOSIP/281382. Acesso em 22 de setembro de 2018. 
RUBIN, Gayle. 2017. "Pensando o sexo". In Políticas do sexo. São Paulo: Editora UBU. (original: "Thinking Sex: Notes for a Radical Theory of the Politics of Sexuality", In Carole Vance, ed., Pleasure and Danger. Routledge \& Kegan Paul, 1984). Disponível em:

https://repositorio.ufsc.br/bitstream/handle/123456789/1229/rubin_pensando_o_sexo.pdf? seq. Acesso em 22 de setembro de 2018.

SANTOS, Gustavo Gomes da Costa. 2016. "Movimento LGBT e partidos políticos no Brasil”. In Revista Contemporânea v. 6, n. 1, p. 179-212 Jan.-Jun. 2016. Disponível em: http://www.contemporanea.ufscar.br/index.php/contemporanea/article/view/393/162.

Acesso em 22 de setembro de 2018.

SARTI, Cynthia. 2004. "O feminismo brasileiro desde os anos 1970: revisitando uma trajetória". In Estudos Feministas. Florianópolis, 12 (12): 35-50, maio-agosto de 2004, p. 36-49. Disponível em: http://www.scielo.br/pdf/ref/v12n2/23959.pdf. Acesso em 22 de setembro de 2018.

SCHUMAHER, Schuma. 2005. "Panorâmica dos 30 anos de feminismo no Brasil". Sexualidade (Boletim do CLAM), ano XII, $\mathrm{n}^{\mathrm{o}}$ especial 23/24/25, outubro de 2005, p. 1-3. Disponível em: < http://www.mulher500.org.br/wp-content/uploads/2017/06/9_Panorama-sobre-ostrinta-anos-do-feminismo-no-Brasil.pdf>. Acesso em 22 de setembro de 2018.

SIMOES, Júlio A.; FACCHINI, Regina. 2009. Na trilha do arco-íris: do homossexual ao movimento LGBT. São Paulo: Editora Fundação Perseu Abramo. Disponível em: https://pt.scribd.com/document/223407706/Facchini-2009-Na-Trilha-Do-Arco-Iris-DoMovimento-Homossexual-Ao-LGBT. Acesso em 22 de setembro de 2018.

SPM. 2016. Disponível em: http://www.spm.gov.br/assuntos/violencia/lei-maria-da penha/spm_livretomariadapenha2015-1.pdf. Acesso em 22 de setembro de 2018.

TRANSRESPECT. 2012. Disponível em: http://transrespect.org/wpcontent/uploads/2015/08/TvT_research-report.pdf. Acesso em 22 de setembro de 2018.

VIANNA, Adriana \& LACERDA, Paula. 2004. Direitos e políticas sexuais no Brasil: mapeamento e diagnóstico. Rio de Janeiro: CEPESC. Disponível em: http://www.clam.org.br/uploads/conteudo/doccompleto.pdf. Acesso em 22 de setembro de 2018. 